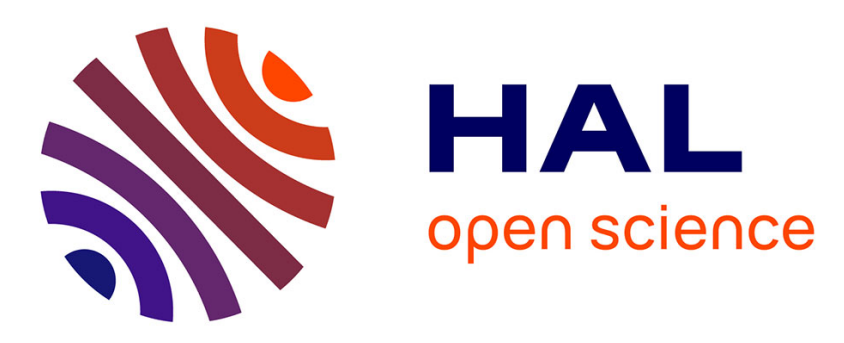

\title{
Light beating spectroscopy measurements of micelles mutual diffusion coefficient within oil in water microemulsions in the presence of sodium chloride
}

\author{
Alain Graciaa, Jean Lachaise, P. Chabrat, L. Letamendia, J. Rouch, C. \\ Vaucamps
}

\section{To cite this version:}

Alain Graciaa, Jean Lachaise, P. Chabrat, L. Letamendia, J. Rouch, et al.. Light beating spectroscopy measurements of micelles mutual diffusion coefficient within oil in water microemulsions in the presence of sodium chloride. Journal de Physique Lettres, 1978, 39 (14), pp.235-238. 10.1051/jphyslet:019780039014023500 . jpa-00231487

\section{HAL Id: jpa-00231487 https://hal.science/jpa-00231487}

Submitted on 1 Jan 1978

HAL is a multi-disciplinary open access archive for the deposit and dissemination of scientific research documents, whether they are published or not. The documents may come from teaching and research institutions in France or abroad, or from public or private research centers.
L'archive ouverte pluridisciplinaire $\mathbf{H A L}$, est destinée au dépôt et à la diffusion de documents scientifiques de niveau recherche, publiés ou non, émanant des établissements d'enseignement et de recherche français ou étrangers, des laboratoires publics ou privés. 


\title{
LIGHT BEATING SPECTROSCOPY MEASUREMENTS OF MICELLES MUTUAL DIFFUSION COEFFICIENT WITHIN OIL IN WATER MICROEMULSIONS IN THE PRESENCE OF SODIUM CHLORIDE
}

\author{
A. GRACIAA, J. LACHAISE \\ Laboratoire de Thermodynamique des Etats Métastables, \\ Institut Universitaire de Recherche Scientifique, 64010, Pau, France \\ P. CHABRAT, L. LETAMENDIA, J. ROUCH and C. VAUCAMPS \\ Laboratoire d'Optique Moléculaire, E.R. 134 du C.N.R.S., \\ Université de Bordeaux I, 33405 Talence, France
}

(Reçu le 27 avril 1978, accepté le 5 juin 1978)

\begin{abstract}
Résumé. - On a mesuré par la technique des battements lumineux, le coefficient de diffusion mutuel des micelles de microémulsions d'huile dans l'eau en présence de $\mathrm{NaCl}$. Les résultats expérimentaux ont été interprétés en remplaçant dans l'expression du coefficient de diffusion d'assemblées de particules en interaction, la viscosité de la phase continue par la viscosité de la microémulsion ellemême. Ils conduisent à une valeur positive du second coefficient du viriel liée à la charge électrique des micelles, et pour les plus fortes concentrations en $\mathrm{NaCl}$, à un rayon micellaire voisin de celui déduit de mesures de pression osmotique.
\end{abstract}

\begin{abstract}
Using light beating spectroscopy we have measured the mutual diffusion coefficient of micelles within oil in water microemulsions in the presence of added $\mathrm{NaCl}$. The experimental results have been explained by replacing the viscosity of the continuous phase, which appears in the diffusion coefficient of systems of interacting particles, by the viscosity of the microemulsion. They lead to a positive second virial coefficient linked with the electric charge of the micelles and, for the highest $\mathrm{NaCl}$ concentrations, to a micellar radius which is close to the radius deduced from osmotic pressure.
\end{abstract}

1. Introduction. - In a previous paper [1] measurements of the mutual diffusion coefficient $D_{\mathrm{T}}$ of water in oil microemulsions have been reported $\left({ }^{1}\right)$. The micellar radius calculated from Stokes-Einstein formula was found in agreement with the value obtained from turbidity data. We report here measurements of $D_{\mathrm{T}}$ for oil in water microemulsions in the presence of added $\mathrm{NaCl}$, using a light beating spectroscopy technique. Micellar radius and second virial coefficient consistent with the experimental values of $D_{\mathrm{T}}$ are compared with osmotic pressure data published by Graciaa et al. [2].

2. Experimental. -2.1 Preparation AND STRUCTURE OF THE MICROEMULSIONS. - The microemulsions are formed from a mixture containing dodecane

( $\left.{ }^{1}\right)$ These results have been very recently confirmed by A. M. Cazabat et al., C. R. Acad. Sci., to be published. (oil ; $4.4 \%$ in weight), sodium dodecyl sulfate (S.D.S. ; $2.4 \%)$, pentanol $(4.8 \%)$, water $+\mathrm{NaCl}(88.4 \%)$. The addition of $\mathrm{NaCl}$ to water has been found necessary to dilute the microemulsions along the limit of the monophasic domain; thus the dilution is obtained by adding a mixture of pentanol and aqueous $\mathrm{NaCl}$ solution in a fixed ratio ( $\approx 1.6 \%$ in weight) [2]. The oil in aqueous $\mathrm{NaCl}$ solution microemulsion obtained exists only in a small range of $\mathrm{NaCl}$ concentration (from 10 to $15 \mathrm{~g} / \mathrm{l}$ ).

The addition of $\mathrm{NaCl}$ lowers the critical micelle concentration $\left({ }^{2}\right)$ enough for the amount of S.D.S. in the continuous phase to be negligible [3]; thus the composition of this phase is that of the added mixture and it is possible to calculate the volume fraction $v$ of the dispersed micelles [2].

$\left({ }^{2}\right)$ The sodium dodecyl sulfate c.m.c. is $2.3 \mathrm{~g} / 1$ in pure water at $25^{\circ} \mathrm{C}$ 
2.2 EXPERIMENTAL TECHNIQUES. - The mutual diffusion coefficient $D_{\mathrm{T}}$ has been measured by using the light beating spectrometer described in [1]. It is deduced from the, time constant of the photocurrent self-correlation function :

$$
D_{\mathrm{T}}=\frac{1}{2 \tau q^{2}}
$$

where $\tau$ is the homodyne correlation time and $q$ is the modulus of the wave vector. This modulus is given by :

$$
q=\frac{4 \pi n}{\lambda} \sin \theta / 2
$$

where $n$ is the refractive index of the sample, $\lambda$ is the wavelength of the $\mathrm{He}-\mathrm{Ne}$ laser light $(0.6328 \mu \mathrm{m})$ and $\theta$ is the scattering angle $\left(90^{\circ}\right)$.

To interpret the experimental values of $D_{\mathrm{T}}$ it is necessary to know the viscosity and the osmotic pressure of the microemulsions. The viscosity has been measured by capillary flow and Couette flow technique, with shear rates of $0.06 \mathrm{~s}^{-1}$ to $15 \mathrm{~s}^{-1}$. The osmotic pressure values that we report here have been measured elsewhere with a « 502 Mechrolab" osmometer [2].

3. Experimental results. - 3.1 Diffusion COEFFICIENT. - We have plotted $D_{\mathrm{T}}$ versus the volume fraction $v$ of the dispersed phase at different $\mathrm{NaCl}$ concentrations (Fig. 1). The behaviour of $D_{\mathrm{T}}$ appears to be very sensitive to the $\mathrm{NaCl}$ concentration : at low concentration, $D_{\mathrm{T}}$ is an increasing function of the volume fraction, whereas it decreases at higher concentration. In this last case, the behaviour of $D_{\mathrm{T}}$ is qualitatively similar to that of water in oil microemulsions.

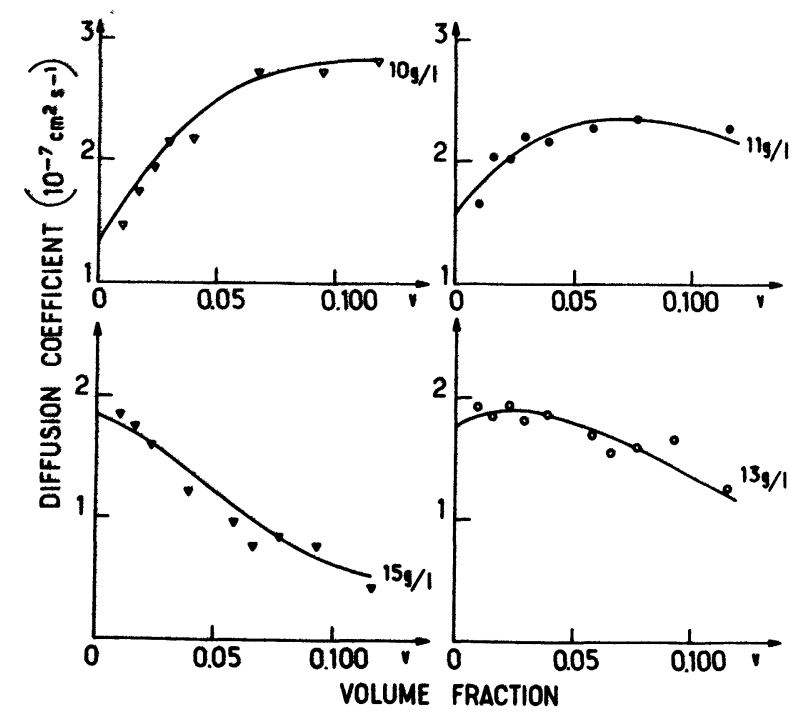

Fig. 1. - Variation of the mutual diffusion coefficient $D_{\mathrm{T}}$ versus the volume fraction $v$ of the dispersed phase at different $\mathrm{NaCl}$ concentrations. The theoretical values (solid line) are calculated from formula (6).
3.2 Viscosity. - The viscosity of the microemulsions shows a Newtonian behaviour for the shear rates used. When the ratio of the specific viscosity of the microemulsion to the volume fraction $v$ is plotted as a function of $v$, figure 2 shows that straight lines are obtained. Thus the experimental results can be represented by :

$$
\frac{\eta-\eta_{0}}{\eta_{0} v}=A+B v
$$

where the viscosity $\eta_{0}$ of the continuous phase is $1.13 \mathrm{cP}$ at $20^{\circ} \mathrm{C}$.

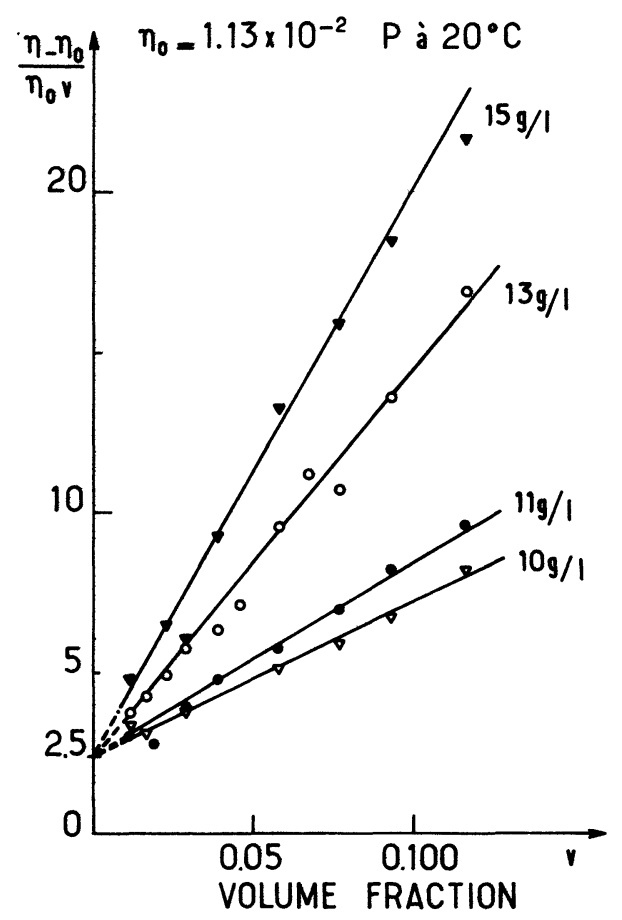

Fig. 2. - Plot of the reduced viscosity $\eta-\eta_{0} / \eta_{0} v$ versus the volume fraction $v$ of the dispersed phase at different $\mathrm{NaCl}$ concentrations. $\eta_{0}$ is the viscosity of the continuous phase equal to $1.13 \times 10^{-2} \mathrm{P}$ at $20^{\circ} \mathrm{C}$.

The intercepts $A$ of the straight lines with the $\left(\eta-\eta_{0}\right) / \eta_{0} v$ axis have been found to be independent of the salt concentration and equal to the Einstein coefficient for the viscosity increment of spherical particles $(A=2.5 \pm 0.1)$. The values of $B$ calculated from the slopes of the straight lines are indicated in table $I$.

This experimental study shows that the viscosity of the microemulsions has the form :

$$
\eta=\eta_{0}\left(1+2.5 v+B v^{2}\right) \text {. }
$$

\section{TABLE I}

\section{Viscosity virial coefficient}

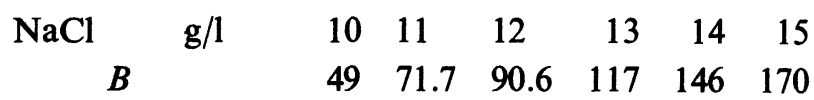


3.3 OSMOTIC PRESSURE. - Direct measurements of the osmotic pressure $\Pi$ of the studied microemulsions [2] have shown that $\Pi$ has the form :

$$
\Pi=\frac{R T}{\mathcal{N} V_{0}}\left(v+B^{\prime} v^{2}\right)
$$

$R, T, \mathcal{N}$ and $V_{0}$ being respectively the perfect gas constant, the absolute temperature, the Avogadro number and the mean volume of the micelles.

The positive values of the second virial coefficient $B^{\prime}$ and of the radius $r_{0}$ of the micelles (deduced from $\left.V_{0}\right)$ are indicated in table II. They are in good agreement with the corresponding values deduced from turbidity measurements.

\section{TABLE II}

Osmotic pressure second virial coefficient and radius of the micelles

$\begin{array}{ccccccc}\mathrm{NaCl} \mathrm{g} / 1 & 10 & 11 & 12 & 13 & 14 & 15 \\ \boldsymbol{B}_{.}^{\prime} & 13.3 & 9.2 & 7.6 & 4.3 & 1.5 & 0 \\ r_{0} \AA & 71 \pm 7 & 73 \pm 7 & 75 \pm 7 & 77 \pm 8 & 83 \pm 8 & 87 \pm 9\end{array}$

4. Discussion. - 4.1 Mutual Diffusion COEFFICIENT. - The concentration fluctuations $\delta C(r, t)$ within the microemulsion which simulates a macromolecular solution obey a Fick's law [4] :

$$
\frac{\partial(\delta C)}{\partial t}=D_{\mathrm{T}} \nabla^{2} \delta C
$$

where the mutual diffusion coefficient $D_{\mathrm{T}}$ is linked to $V_{0}$ and $\Pi$ by the relation :

$$
D_{\mathrm{T}}=\frac{V_{0}}{f} \frac{\partial \dot{I}}{\partial v_{\mathrm{PT}}}
$$

$f$ being a friction coefficient. The expression (5) is a generalization of the Stokes-Einstein diffusion coefficient to a system of interacting particles where the coefficient $f$ is related to dissipative forces such as collisions [5]. By assuming that $f=6 \pi r_{\mathrm{H}} \eta$, where $r_{\mathrm{H}}$ is the hydrodynamic radius of the micelles and $\eta$ is the viscosity of the microemulsion given by equation (2) $\left({ }^{3}\right)$, the theoretical value of $D_{\mathrm{T}}$ is given by :

$$
D_{\mathrm{T}}=\frac{k T}{6 \pi r_{\mathrm{H}} \eta_{0}}\left(\frac{1+2 B^{\prime} v}{1+2.5 v+B v^{2}}\right) \text {. }
$$

It can be verified that for the low values of $v, D_{\mathrm{T}}$ is equivalent to the Stokes-Einstein coefficient of rigid non-interacting spheres.

$D_{\mathrm{T}}$ has been calculated for different $\mathrm{NaCl}$ concentrations by using coefficients $B$ and $B^{\prime}$ of the preceding tables, and adjusting the value of $r_{\mathrm{H}}$ to give the best fit with the experimental points. The calculated values of $D_{\mathrm{T}}$ are the continuous curves drawn in figure 1 . Their agreement with the experimental points confirms the positive values of the second virial coefficient $B^{\prime}$ of the osmotic pressure obtained from direct measurements; this also confirms the former hypothesis that the size and the shape of the micelles are not affected by the dilution of the microemulsion.

4.2 Hydrodynamic Radius. - The adjusted values of $r_{\mathrm{H}}$ are reported in the table III where they are compared with the radius $r_{0}$ deduced from osmotic pressure measurements. It can be seen that $r_{\mathrm{H}}$ and $r_{0}$ have opposite dependences on $\mathrm{NaCl}$ concentration : at low concentration $r_{\mathbf{H}}$ is twice $r_{0}$, whereas with increasing concentration the difference between the two values tends to diminish.

Such a strong dependence of $r_{\mathrm{H}}$ on salt concentration has been observed by Pusey [6] in virus R17 (macro-ions) solutions. This effect has been related to a change in the ionic atmosphere with increasing salt concentration. The screening effect of this atmosphere makes a macro-ion of radius $r_{0}$ behave as a hard sphere of radius $r_{0}+k^{-1}$ where $k$, the DebyeHückel parameter, is proportional to the square root of the concentration of the small counterions $\left(\mathrm{Na}^{+}\right)$. As the hydrophilic polar heads of S.D.S. molecules are partially ionized, the micelles of the microemulsion behave like macro-ions. However, over the range of $\mathrm{NaCl}$ concentrations of the continuous phase, $k^{-1}$ falls only from $8 \AA$ to $6.5 \AA$ and this change is too small to explain the observed phenomena.

The osmotic pressure depends only on the volume of the particles while the diffusion coefficient is also sensitive to their shape. As Mazer, Benedek and Carey [8] showed (under some conditions of temperature and of added $\mathrm{NaCl}$ concentration, the micelles of aqueous solutions of S.D.S. are approximated by

$\left({ }^{3}\right)$ This last hypothesis is justified by the fact that for the studied microemulsions, the mean distance between the micelles is near enough to their radius to consider micelle-micelle collisions as rapid processes. The proportionality factor $6 \pi$ is suggested because the microemulsions simulate macromolecular solutions; thus the spherical micelles are moving within a statistical homogeneous phase.

TABLE III

Hydrodynamic and "Osmotic pressure " radius of the micelles

$\begin{array}{lccccccc}\mathrm{NaCl} & \mathrm{g} / 1 & 10 & 11 & 12 & 13 & 14 & 15 \\ r_{\mathrm{H}} & \AA & 142 \pm 14 & 133 \pm 13 & 108 \pm 11 & 108 \pm 11 & 97 \pm 10 & 104 \pm 10 \\ r_{0} & \AA & 71 \pm 7 & 73 \pm 7 & 75 \pm 7 & 77 \pm 8 & 83 \pm 8 & 87 \pm 9\end{array}$


prolate ellipsoids), it should seem possible to attribute the observed discrepancy between $r_{0}$ and $r_{\mathrm{H}}$ to $\mathrm{A}$ conformational change with the variation of the ionic strength of the aqueous phase. Unfortunately, this picture is not in agreement with the experimental value of the coefficient for the viscosity increment; it is well known that for ellipsoids this coefficient is larger than 2.5 [7].

Another possibility could be that for the lowest $\mathrm{NaCl}$ concentrations, the micelles behave like solvated macromolecules which carry with them a part of the solvent; but this assumption is also hard to reconcile with the values of the viscosity increment.

4.3 SECOND VIRIAL COEFFICIENT. - The values of $B^{\prime}$ have been explained [9] by putting :

$$
B^{\prime}=B_{0}^{\prime}+B_{\mathrm{D}}^{\prime}
$$

where $B_{0}^{\prime}$ is the negative second virial coefficient of the osmotic pressure of microemulsions of neutral micelles [11] and $B_{\mathrm{D}}^{\prime}$ is a positive virial term which must be attributed to the electric charges on the micelles (Donnan's effect). $B_{\mathrm{D}}^{\prime}$ has the form :

$$
B_{\mathrm{D}}^{\prime}=\frac{1000 Z^{2}}{4 m \mathcal{N} V_{0}}
$$

where $Z$ is the number of charges on the micelles and $m$ is the molality of the aqueous phase [7]. It has been found that the values of $B^{\prime}$ given by equations (7) and (8) are in agreement with the experimental values in table II when $Z$ is approximately 100 . This number of charges leads to an apparent degree of ionization which varies from 0.21 to 0.08 with the $\mathrm{NaCl}$ concentration increment.

5. Conclusion. - We have measured the mutual diffusion coefficient of oil in water microemulsions in the presence of added $\mathrm{NaCl}$. The experimental results have been explained by applying a generalization of the Stokes-Einstein diffusion coefficient to systems of interacting particles as is the case for the studied microemulsions. As the mean distance between the micelles is near enough to their radius to consider micelle-micelle collisions as rapid processes, the viscosity of the continuous phase which appears in the usual expression of the generalized Stokes-Einstein diffusion coefficient has been replaced with success by the viscosity of the microemulsion.

Second virial coefficients consistent with the experimental values of $D_{\mathrm{T}}$ are in good agreement with the osmotic pressure data. Their positive values have been explained by adding the positive contribution of the Donnan's effect to the negative virial term of neutral micelles.

The agreement between light beating spectroscopy and osmotic pressure technique is also found for the micellar radius when the $\mathrm{NaCl}$ concentration is sufficiently high. For the lowest $\mathrm{NaCl}$ concentrations, the hydrodynamic radius is higher than the osmotic pressure radius.

Acknowledgments. - We are indebted to the referees of this paper for their constructive suggestions.

\section{References}

[1] Graciaa, A., Lachaise, J., Chabrat, P., Letamendia, L., Rouch, J., Vaucamps, C., Bourrel, M., Chambu, C. J. Physique Lett. 38 (1977) 253.

[2] Graciaa, A., Lachaise, J., Martinez, A., Rousset, A., C.R. Acad. Sci. Paris B 285 (1977) 295.

[3] Mysels, K. J., Princen, L. H., J. Phys. Chem. 63 (1959) 1696.

[4] Berne, B. J., Pecora, R., Dynamic Light Scattering (Wiley), 1976.

[5] Phillies, G. D. J., J. Chem. Phys. 60 (1974) 976.

[6] Pusey, P. N., Photon Correlation and Light Beating Spectroscopy, Cummins H. Z., Pike E. R. (Plenum Press), 1974

[7] TANFORD, C., Physical chemistry of macromolecules (Wiley), 1961 .
[8] Mazer, N. A., Benedek, G. B., Carey, M. C., J. Phys. Chem. 80 (1976) 1075.

[9] GraciaA, A., Lachaise, J., Martinez, A., Rousset, A., C.R. Acad. Sci. Paris B 286 (1978) 157.

[10] GraciaA, A., Thesis, Pau 1978, to be published.

[11] The mean value of $B_{0}^{\prime}$ has been found to be -5 for water/oil microemulsions with ionic surfactant and for oil/water microemulsions with anionic surfactant $[9,10]$. A tentative explanation of this effect has been given by Agterof $e$ t al., Chem. Phys. Lett. 43 (1976) 363 and Micellization, Solubilization and Microemulsions, vol. 2. K. L. Mittal Ed. (Plenum N.Y.). 1977. 